\title{
The Procedure of Solving the Inverse Problem for Determining Surface Heat Transfer Coefficient between Liquefied Nitrogen and Inconel 718 Workpiece in Cryogenic Machining
}

\author{
Matija Hriberšek ${ }^{1, *}$ - Viktor Šajn ${ }^{1}$ - Franci Pušavec ${ }^{1}$ - Joel Rech ${ }^{2}$ - Janez Kopač ${ }^{1}$ \\ ${ }^{1}$ University of Ljubljana, Faculty of Mechanical Engineering, Slovenia \\ 2 University of Lyon, Ecole Nationale d'Ingenieurs de Saint-Etienne, France
}

The determination of the cooling effect is important since the phase (liquid and gaseous) has a significant influence on the cooling effect, which indirectly influences the integrity of the machined surface after machining process. Therefore, this paper presents how the phase of liquefied nitrogen influences the surface heat transfer coefficient. The determination of the phase has been defined by resolving the inverse problem with conducted experiments and verified by the design of a numerical simulation. The experimental part includes the temperature measurement in the material (a plate of Inconel 718) at the time when the nozzle has moved across the plate, and the design of the numerical simulation. The results have shown that the surface heat transfer coefficient reaches the maximum value of $75000 \mathrm{~W} /\left(\mathrm{m}^{2} \mathrm{~K}\right)$ at the temperature difference (between liquefied nitrogen-Inconel 718 plate) of $196 \mathrm{~K}$ (liquid phase of the nitrogen). Steep value decrease for heat transfer coefficent $\left(15000 \mathrm{~W} /\left(\mathrm{m}^{2} \mathrm{~K}\right)\right)$ at temperature difference $160 \mathrm{~K}$ (pure gaseous phase of the nitrogen) has been detected.

Keywords: liquefied nitrogen, cryogenic machining, numerical simulation, surface heat transfer coefficient

Highlights

- Performation of experimental temperature measurements with thermocouples in Inconel 718 plate.

- Design of numerical simulation and experimental validation of results.

- Determination of the surface heat transfer coefficient for nitrogen comparing liquid and gaseous phase.

- $\quad$ Specification of the differences between the liquid and gaseous phase of nitrogen.

\section{INTRODUCTION AND STATE OF THE ART}

When planning production processes, the most important task is to obtain the best machine part quality with minimum manufacturing costs. The environmental aspects have also become significantly important [1], which is connected with striving to achieve a higher level of productivity and environmental awareness.

This idea has been recognized in terms of sustainable manufacturing. This includes minimizing the use of cooling lubrication fluids based on artificial ingredients and increasing cutting speeds. The way of supplying and the quantity cooling lubrication liquids delivered to the cutting zone largely influence machinability of constructional materials [2]. The use of ecologically impeccable cooling lubrication fluids that do not harm people's health and are environmentfriendly has been promoted. Such cooling lubrication fluids are for instance liquefied nitrogen and vegetable-based oils. In connection with such fluids, more and more sustainable alternative technologies have been developing. One of them is cryogenic machining, where liquefied nitrogen can be used as a cooling lubrication fluid [3]. These facts encouraged the present research on how liquefied nitrogen functions as a cooling lubrication fluid, in order to enable its use in industry in future to encourage green production.

Materials such as high temperature alloys (nickel, titanium, etc.) are usually employed in manufacturing processes of high added valued products, especially in space, aircraft and military industry [4]. Such materials have excellent mechanical and thermal properties which are maintained even when the materials are exposed to high temperatures. Additionally, such materials have low thermal conductivity and get plastically hardened at high temperatures, hence their extremely poor machinability [5]. At the formation of a chip, high temperatures and deformations occur in contact zones, which causes fast tool wear or even cutting edge fractures [6]. According to these facts, it can be concluded that such materials should be machined by the use of a cooling fluid, such as liquefied nitrogen. For conducting this research, Inconel 718 was chosen. Inconel 718 is a nickelchromium alloy and is one of high-temperature alloys.

The main property of cryogenic machining is the use of a cryogenic fluid (liquefied nitrogen) as the cooling fluid during cutting processes at very low temperatures. The dividing line between cryogenic and conventional temperatures is in evaporation point that should be below $-150{ }^{\circ} \mathrm{C}$ [7]. The idea is based on the delivering of a cryogenic fluid (liquefied 
nitrogen) to the local zone on the cutting edge where the temperature during cutting is the highest [8].

Based on the researches of the temperature in the cutting zone, Ding and Hong [9] has explained that the use of liquefied nitrogen increases tool life and achieves better material machinability (shorter chips), compared to conventional processes. Dhokia et al. [10] has proven that the surface quality after cryogenic machining is better (lower roughness), compared to the cutting processes at which conventional cooling lubrication fluids are used.

$\mathrm{Pu}$ et al. [11] has conducted experiments to prove that compressive residual stresses in a material after cryogenic machining are favorable since they prevent cracks on the surface.

Reviewing the state of the art in the field of observation phase of nitrogen, the majority of previous studies have been conducted with the purpose to research the macrocharacteristics of heat transfer when boiling [12]. Tsukamoto and Uyemara [13] have presented an optical way of observing bubble formation at the surface of a thin wire, heated by a stepwise transient in liquid nitrogen. Kida et al. [12] has conducted researches in the field of the microcharacteristics of boiling, analyzing the size and the frequency of nitrogen bubble formation.

The aim of the paper is to contribute to better understanding of the influence of liquefied nitrogen in terms of defining the surface heat transfer coefficient in correlation to its phase, by resolving the inverse problem. Studies in terms of defining surface heat transfer coefficient between liquefied nitrogen and surface workpiece have been encouraged by not knowing exactly values for this coefficient published in the past publications.

Most papers dealing with this topic use the surface heat transfer coefficient values referenced from the following papers: Hong and Ding [14] $\left(h_{L N}=23270\right.$ $\mathrm{W} /\left(\mathrm{m}^{2} \mathrm{~K}\right)$ to $46750 \mathrm{~W} /\left(\mathrm{m}^{2} \mathrm{~K}\right)$ and Hong and Ding [15] $\left(h_{L N}=48270 \mathrm{~W} /\left(\mathrm{m}^{2} \mathrm{~K}\right)\right.$ to $74950 \mathrm{~W} /\left(\mathrm{m}^{2} \mathrm{~K}\right)$.

The paper presents the analysis of the difference between the influence of the liquid and gaseous phase of nitrogen on in-depth temperature and depth of the cooling layer in Inconel 718 workpiece. This simulates the temperature distribution in the cutting zone during machining, what indirectly influences the friction coefficient, the surface integrity of the workpiece, and the functionality of a final component/product [16].

\subsection{Theoretical Background}

\subsubsection{The Difference between Liquid and Gaseous Phase}

The paper presents the difference between the influence of the liquid and gaseous phase of nitrogen in terms of determining the surface heat transfer coefficient depending on the temperature of the fluid/ workpiece. An important characteristic of nitrogen is its phase. Due to its extremely low evaporation temperature $(T)\left(-196{ }^{\circ} \mathrm{C}\right.$ at air pressure $(p)$ of $\left.10^{5} \mathrm{~Pa}\right)$, liquefied nitrogen has a high tendency to evaporate and consequently, the phase (liquid and gaseous) can change when liquefied nitrogen exits the nozzle. Physical properties of this fluid for both phases, such as density $(\rho)$, specific heat $\left(C_{p}\right)$, viscosity $(v)$, and thermal conductivity $(\lambda)$ are listed in Table 1 [17].

Table 1. Differences in physical properties between liquid and gaseous phase at $T=-196{ }^{\circ} \mathrm{C}$ (both phases) and $p=10^{5} \mathrm{~Pa}$ (both phases)

\begin{tabular}{lcc}
\hline & \multicolumn{2}{c}{ Phase of the media } \\
\hline Physical properties of nitrogen & $N_{1}$ (liquid) & $N_{2}$ (gaseous) \\
\hline$\rho\left[\mathrm{kg} / \mathrm{m}^{3}\right]$ & 803.6 & 4.979 \\
\hline$C_{p}[\mathrm{~J} /(\mathrm{kgK})]$ & 2046 & 1351 \\
\hline$v[\mathrm{~Pa} \cdot \mathrm{s}]$ & $1.463 \cdot 10^{4}$ & $0.05331 \cdot 10^{-4}$ \\
\hline$\lambda[\mathrm{W} /(\mathrm{mK})]$ & $1.320 \cdot 10^{-1}$ & $0.07658 \cdot 10^{-1}$ \\
\hline
\end{tabular}

Fig. 1 presents the phases of nitrogen.

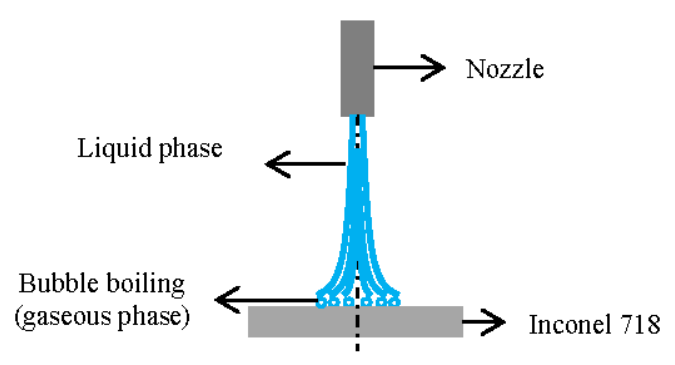

Fig. 1. Phases of nitrogen (liquid and gaseous)

\subsubsection{Thermal Conditons at Cooling with Liquefied Nitrogen}

The function of the application of liquefied nitrogen to the local area of a tool or to a workpiece (toolworkpiece contact) is the cooling of the machining process. It is a process of convection (cooling), where a cold flow of the fluid comes to the surface of a warmer body and creates a boundary layer that fits the surface of the body. That is assumed to be the gaseous layer of nitrogen which has lower thermal 
conductivity than pure liquid phase (Fig. 1). In this way the nitrogen film modeling has been designed in the numerical simulation [18].

For performing experiments in this work, the plate has been cooled by the moving nozzle, where convective (forming thin film on the workpiece surface) and diffused (heat transfer through the solid body) heat transfer occurs. Convective heat transfer occurs when a thin film is formed on the workpiece surface and when boiling bubbles start moving upwards in the atmosphere because of the pushing force. Advection needs to be taken into account, too, and it is a phenomenon when energy (including thermal energy) is moved by the physical transfer of a hot or cold object from one place to another. This can be described by the Eq. (1) [19]:

$$
Q=v_{f} \rho C_{p} \Delta T,
$$

where $Q[\mathrm{~W}]$ is heat flux, $\Delta T[\mathrm{~K}]$ temperature difference and $v_{f}[\mathrm{~m} / \mathrm{s}]$ velocity of the flux.

From the physical point of view, the process can be described by Fouriers law, which is defined as: the heat flux density $q\left[\mathrm{~W} / \mathrm{m}^{2}\right]$, resulting from thermal conduction, is proportional to the magnitude of the temperature gradient and opposite to it in sign. The law can be defined in the Cartesian coordinate system and is defined by Eq. (2):

$$
\vec{q}=-\lambda \cdot\left(\frac{\partial T}{\partial x}, \frac{\partial T}{\partial y}, \frac{\partial T}{\partial z}\right) .
$$

This means that if temperature decreases with distance, the heat flux density $q$ is positive and in the direction of distance vector. If temperature $T$ increases with the distance vector $\vec{r}$, the heat flux density $q$ is negative and in the opposite direction of the distance vector $\vec{r}$ [18]. Heat flux density, accepted by the body, is defined by Eq. (3):

$$
\begin{gathered}
q=h\left(T_{b o d y}-T_{\text {fluid }}\right), \quad q=\frac{\partial T}{\partial z}, \\
T_{\text {body }}=25^{\circ} \mathrm{C}, \quad T_{\text {fluid }}=-196{ }^{\circ} \mathrm{C},
\end{gathered}
$$

where $T_{\text {fluid }}\left[{ }^{\circ} \mathrm{C}\right]$ is fluid temperature and $T_{\text {body }}\left[{ }^{\circ} \mathrm{C}\right]$ body temperature.

The surface heat transfer coefficient $h$ [W/ $\left.\left(\mathrm{m}^{2} \mathrm{~K}\right)\right]$ is in thermodynamics and mechanics a proportional coefficient to the heat flux density, which flows through the surface layer, and the temperature difference [20] and [21].

Additionally, the convective heat transfer, that is present when the difference between the temperature of the workpiece surface and the fluid exists has to be taken into account, too. This phenomenon refers to the thermal boundary layer which causes the surface heat transfer. Additionally, there is also a velocity boundary layer due to the friction between the surface and the fluid which is the result of the fluid viscosity [22] and has to be taken into account.

\section{METHODS}

At first, a numerical simulation (finite element method) has been designed to describe experimental condition and to resolve the inverse problem for determining the surface heat transfer coefficient between liquefied nitrogen and Inconel 718 workpiece plate.

Eulerian formulation, which is fixed in space and can be used to simulate the flow through the material mesh, has been used [23].

When at least one parameter of the process is not known, different methods can be used to resolve inverse problem [24]. In the experimental part of measuring temperature, the surface heat transfer coefficent was not known. The focus of the numerical simulation was to determine the surface heat transfer coefficent, based on fitting the experimental $T_{\exp }(t)$ and the simulation $T_{\text {sim }}(t)$ curve.

Fig. 2 displays the sequence of the operations that have been conducted to determine the surface heat transfer coefficient between liquefied nitrogen and Inconel 718. At the beginning, the values for the heat transfer coefficient from literature have been selected [14] and [15].

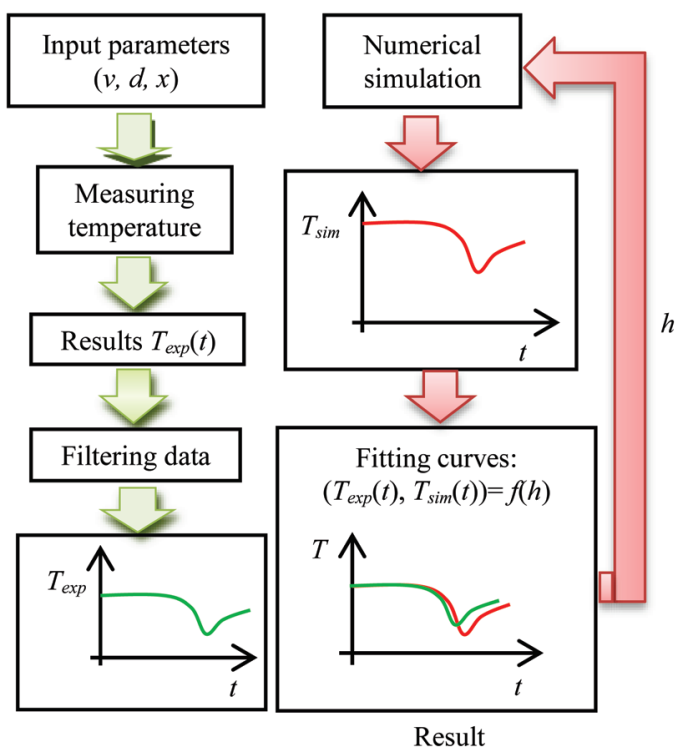

Fig. 2. Procedure for defining the surface heat transfer coefficient between liquefied nitrogen and the workpiece surface (Inconel 718) 
To reach the fitting of the experimental curve $T_{\text {exp }}(t)$ and the simulation curve $T_{\text {sim }}(t)$, the exact values for the surface heat transfer coefficient, depending on the difference of the temperature between the coolant and the workpiece, have been determined.

Additionally, the values for the surface heat transfer coefficient have been checked to coincide with the value interval from the literature.

\section{THE EXPERIMENTAL PART}

The workpiece was an Inconel 718 plate $(150 \mathrm{~mm} \times$ $246 \mathrm{~mm} \times 2.5 \mathrm{~mm}$ ) which was hot-rolled, aged and polished at $R_{a}<0.3 \mu \mathrm{m}$ on the upper side. On the lower side of the plate, 3 sets of 5 holes within the distance of $5 \mathrm{~mm}$ were made. Each set of the holes was at the following depths: $0.1 \mathrm{~mm}, 0.5 \mathrm{~mm}$ and 1 $\mathrm{mm}$ from the polishing side of the plate. Three sets of holes were machined because of the future researches of the temperature field along the depth of the Inconel 718 plate.

The nozzle was moved across the middle of the plate, right above the middle hole on the grinded surface of the plate. In the experiments, five thermocouples NiCr-Ni (K-type, diameter $0.3 \mathrm{~mm}$ ) were used. The thermocouples were fixed to the holes with a power tape. To assure the contact of the thermocouple with the workpiece, the thermopaste based on silicon oil with metal oxides was used. The nozzle diameter was $1 \mathrm{~mm}$ and moved $15 \mathrm{~mm}$ above the plate. Liquefied nitrogen was piped through the nozzle under pressure of $p=1.8 \cdot 10^{5} \mathrm{~Pa}$. For data acquisition, a NI acquisition card was used, while for the nozzle movement, the nozzle was attached to the machine spindle and moved along the plate. Firstly, the input parameters were determined and with it the design of experiments. The parameters were: the measuring temperature in correlation to the nozzle moving speed $v[\mathrm{~m} / \mathrm{min}]$, depth $d[\mathrm{~mm}]$ and the distance from the neutral line $x[\mathrm{~mm}]$ (in the middle of the plate). The temperature in the material $(T)$ was measured, depending on the changing of the input parameters $(v, d$ and $x)$. The value range for the moving nozzle speed was defined based on comparable cutting speed, recommended for machining Inconel 718. By the determination of the values, the aim was to determine the temperature drop in the material after the nozzle had moved across the plate. This can be compared to one workpiece revolution in the turning process. The design of experiments comprised 12 experiments at different nozzle moving speeds $(5,15$, 25 or 35$) \mathrm{m} / \mathrm{min}$ and at different depths at which the temperature in the material was measured $(0.1 \mathrm{~mm}$,
$0.5 \mathrm{~mm}$ or $1 \mathrm{~mm})$. Fig. 3 shows the experimental setup (the clamping of the nozzle onto the machine spindel and the detail that shows the diameter of the jet dispersion on the surface).

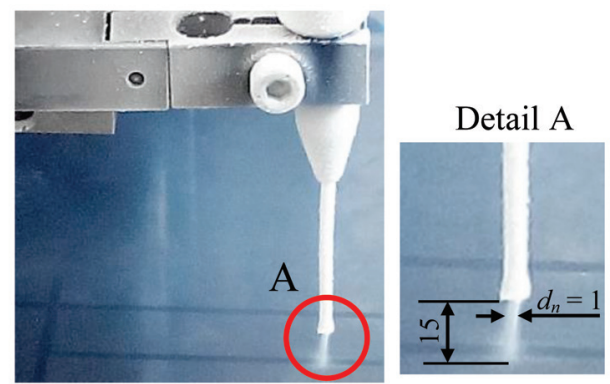

Fig. 3. Cooling of the Inconel 718 plate with liquefied nitrogen (diameter of the nozzle $d_{n}=1 \mathrm{~mm}$, distance nozzle-plate $15 \mathrm{~mm}$ )

Fig. 4 shows the direction of the nozzle movement (the arrow) and the location of the thermocouples in different colours.
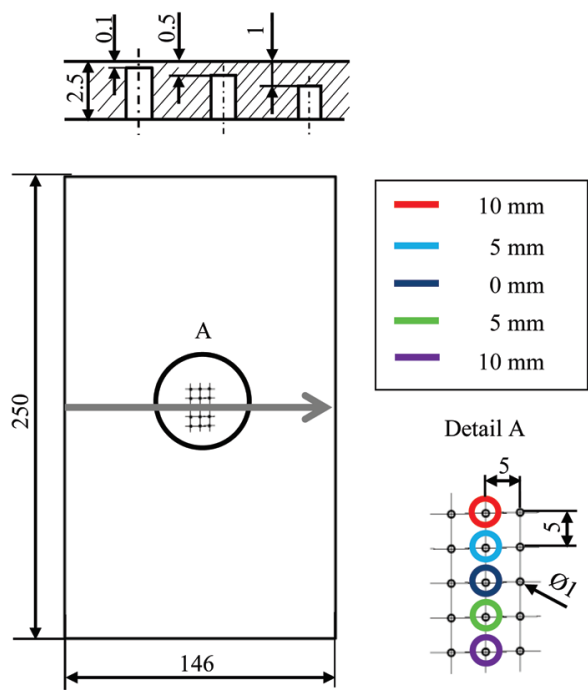

Fig. 4. Shematic illustration of the moving nozzle with corresponding positions of the thermocouples and a cross section view of the holes at different depths

Fig. 5 shows the measured temperature-time distribution for moving speed of $v=5 \mathrm{~m} / \mathrm{min}$. There are five temperature-time curves for each thermocouple positioned at the same depth $(d=0.5$ $\mathrm{mm})$ to provide enough information for describing temperature field in the plate.

The process of moving the nozzle across the plate lasted for $1.8 \mathrm{~s}$, the difference to $2.4 \mathrm{~s}$ was predicted for balancing the heat flux in the system. It shows that the change in the material temperature is the biggest in the middle thermocouple marked with blue $\Delta T=5.5 \mathrm{~K}$. 
The result is in accordance with the expectations since the nozzle moved across the middle of the plate. The minimum temperature was reached after $1.1 \mathrm{~s}$, which means that there had been a delay in the process.

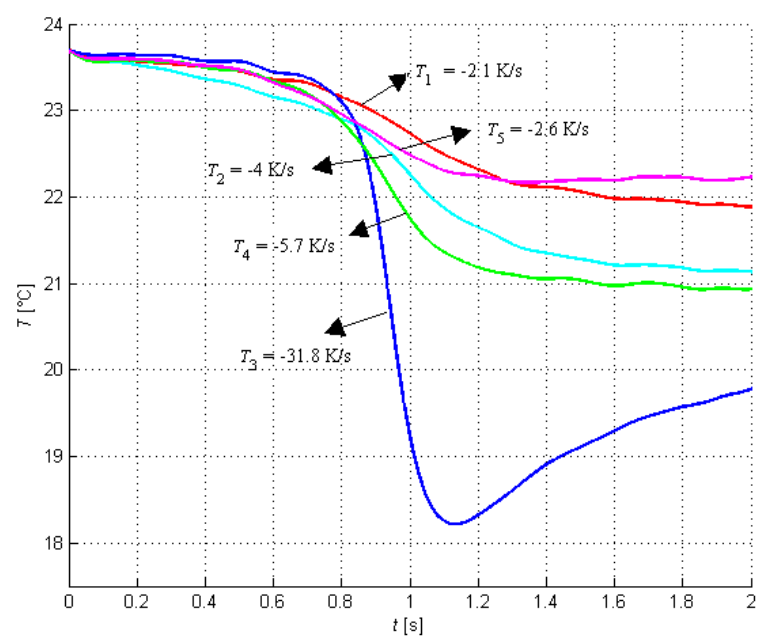

Fig. 5. Temperature time distribution curve $T_{\text {exp }}(t)$ for Inconel 718 and time of the moving nozzle across the plate $t=1.8 \mathrm{~s}$

$(v=5 \mathrm{~m} / \mathrm{min}$ and measured temperature at depth: $0.5 \mathrm{~mm}$ )

The reason for this phenomenon is the forming of a gaseous nitrogen film which causes convective cooling of the material surface. While the nozzle was moving across the plate, it gradually pounded the convective insulated film which prevented higher cooling of the material.

The cooling rate is described by Eq. (4):

$$
\left(\frac{d T}{d t}\right)_{\max }=\frac{T_{\max }-T_{\min }}{t_{2}-t_{1}}
$$

where $T_{\max }$ is temperature maximum and $T_{\min }$ is temperature minimum on the steepest part of the $T(t)$ curve. The results are shown in Table 2, where the cooling rates for all the mentioned curves are shown.

The results listed in Table 2 show that the middle thermocouple $T_{3}$ was subjected to cooling the most $-31.8 \mathrm{~K} / \mathrm{s}$ at the depth of $0.5 \mathrm{~mm}$ below the surface of Inconel 718. One of the reasons for slow cooling of Inconel 718 is also that it has low thermal conductivity $(11.3 \mathrm{~W} /(\mathrm{mK}))$, as well as the above mentioned gaseous nitrogen film that is formed by the process of convection. For the numerical simulation design, the following parameters were chosen: $v=5 \mathrm{~m} / \mathrm{min}$, $d=0.5 \mathrm{~mm}, x=0 \mathrm{~mm}$ and $\Delta T=5.5 \mathrm{~K}$, represented by curve $T_{3}$.

The cooling rate is also calculated, depending on the duration of the experiment, where the temperature at $0.1 \mathrm{~mm}$ below the surface was measured. The liquefied nitrogen jet was static and applied for such a long time until the balance between the liquid nitrogen jet and the temperature at the depth of $0.1 \mathrm{~mm}$ in Inconel 718 was reached. Fig. 6 shows the conducted experiment.

Table 2. Maximum temperature rates at depth $0.5 \mathrm{~mm}$ from the surface

\begin{tabular}{|c|c|c|}
\hline $\begin{array}{c}\text { Number of } \\
\text { the curve }\end{array}$ & $\begin{array}{c}\text { Distance from the } \\
\text { moving nozzle } x[\mathrm{~mm}]\end{array}$ & $\left(\frac{d T}{d t}\right)_{\max }[\mathrm{K} / \mathrm{s}]$ \\
\hline$T_{1}$ & 10 & -2.1 \\
\hline$T_{2}$ & 5 & -4.0 \\
\hline$T_{3}$ & 0 & -31.8 \\
\hline$T_{4}$ & 5 & -5.7 \\
\hline$T_{5}$ & 10 & -2.6 \\
\hline
\end{tabular}

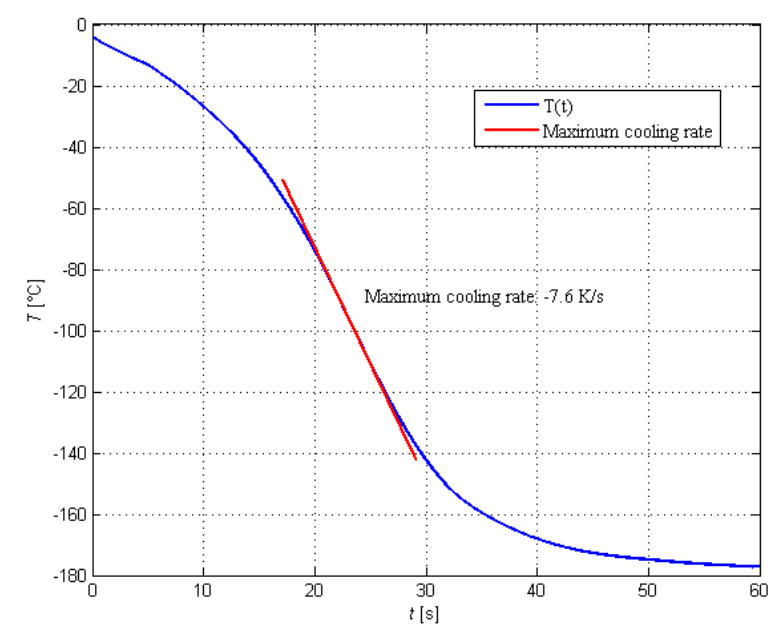

Fig. 6. Temperature time distribution curve (experiment) corresponding to static nozzle and, measuring temperature at depth $d=0.1 \mathrm{~mm}$

The maxiumum cooling rate on the curve (Fig. 6) was calculated to be $-7.6 \mathrm{~K} / \mathrm{s}$. The static experiment was conducted in order to show the impact of the static nozzle on the cooling rate of the Inconel 718 plate. The experiments with a moving nozzle show that there is a greater impact on the pounding of the convection gaseous film of nitrogen because the cooling rates were reached in a shorter time compared to the static nozzle experiment.

The static experiment tells that a static liquefied nitrogen jet has a lower capability to pound the gaseous nitrogen film, which consequently prolongs the time needed to reach the temperature balance. The convection of ambient air has impact on slower cooling of the plate. 


\section{NUMERICAL SIMULATION - SURFACE HEAT TRANSFER COEFFICIENT}

In the current case, the numerical simulation was designed in Abaqus/Explicit 6.10. Finite element method was used. For simulating heat transfer through the mesh on the material, while using a fluid, the Eulerian formulation was used [23] and [25].

The reference parameters for the design of the numerical simulation were the following: $v=5 \mathrm{~m} / \mathrm{min}$, $d=0.5 \mathrm{~mm}$ in $x=0 \mathrm{~mm}$. The depth of $0.5 \mathrm{~mm}$ was chosen since it had proven to be the most appropriate for simulating. At the depth of $0.1 \mathrm{~mm}$, errors could have occured (measuring the temperature right under the surface).

The input parameters were: type of the formulation, mesh, the nozzle speed, the material mechanical and thermal properties data, as well as the initial and boundary conditions. The output parameter was the temperature. The mesh was chosen according to the geometry of each individual element in the system. The mesh was tetrahedral. All created components (the plate, the thermopaste and the thermocouple) had a finer net in the area of measuring temperature (Fig. 7). The length side of the triangle is marked with $a$ (Fig. 7).

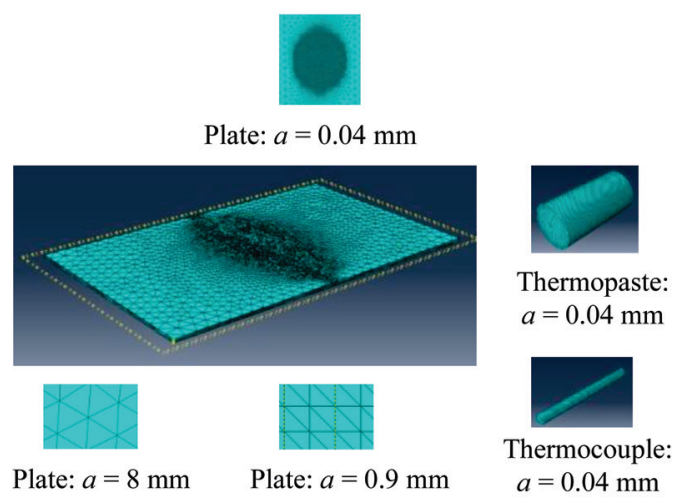

Fig. 7. Mesh mode of the system

Thermocouple and thermopaste were also created in the numerical simulation because of their different thermal properties, in order to describe the experiment completely and to reach the best possible result in the numerical simulation.

Fig. 8 shows the numerical simulation boundary conditions.

Dispersion of the liquefied nitrogen jet on the surface was assumed to be $4 \mathrm{~mm} \times 4 \mathrm{~mm}$. Two rectangles on the Fig. 8 present the liquefied nitrogen jet.

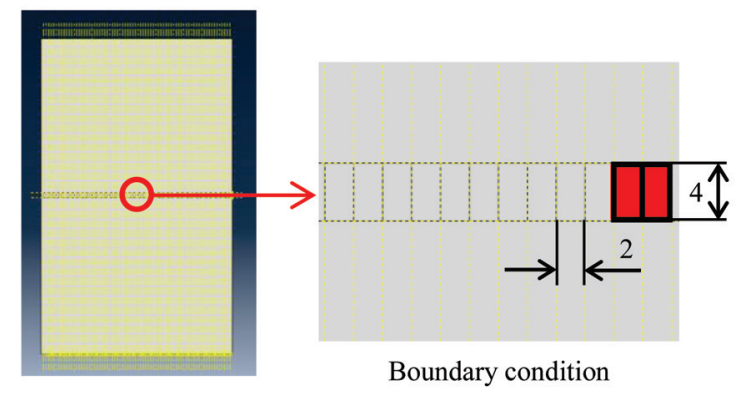

Fig. 8. Boundary condition; the starting temperature of the system was $25^{\circ} \mathrm{C}$ (initial boundary condition)

Based on the width of the plate $(146 \mathrm{~mm})$, there were 73 rectangles. Based on the selected nozzle velocity $(5 \mathrm{~m} / \mathrm{min})$ and the width of the particle ( $2 \mathrm{~mm})$, the time period of the jet application was calculated. The temperature of the surface of each particle was $-196^{\circ} \mathrm{C}$.

Mechanical (Young's modulus, Poisson ratio and density) and thermal (thermal conductivity and specific heat) properties of the materials used in the numerical simulation were adapted from the literature [26] to [28]. Because of a little temperature difference in Inconel 718, temperature dependant data for its properties were not considered. The thermocouple material for simulation was nickel which has approximately the same mechanical and thermal properties as chromium.

Temperature dependant thermal properties for the liquid nad gaseous phase of the nitrogen were adapted from Pušavec et al. [4]. The time gradient was $0.05 \mathrm{~s}$.

According to the fitting of the two curves, the experimental $T_{\text {exp }}(t)$ and the simulation $T_{\text {sim }}(t)$, the thermal conductivity of the gaseous nitrogen film was determined $(\lambda=30 \mathrm{~W} /(\mathrm{mK}))$, as well as the surface heat transfer coefficient between liquid nitrogen and the workpiece.

According to this fact, it can be concluded that bubble boiling of the cryogenic media was suspected. It is assumed that the bubbles were dispersed and that they formed a gaseous nitrogen film.

Fig. 9 shows the temperature distribution in the nodals on the plate after the numerical simulation $\left(t_{\text {sim }}=2.4 \mathrm{~s}\right)$. In the numerical simulation, the cooling impact of the liquefied nitrogen jet on the whole surface of the Inconel 718 plate was taken into account. On the right side of the plate there is a wider area of cooling impact as a start point of entry to the nozzle plate. Fig. 10 shows the temperature distribution in the nodals across the depth of the plate after numerical simulation $\left(t_{\text {sim }}=2.4 \mathrm{~s}\right)$. The cooling impact of the liquefied nitrogen decreases with the 
increasing distance from the center where there were boundary conditions - velocity and the size of the surface jet on the plate.

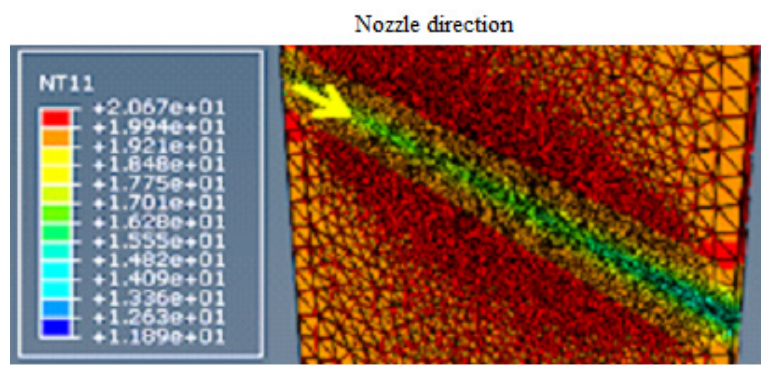

Fig. 9. Temperature distribution on the plate after numerical simulation, $t_{\text {sim }}=2.4 \mathrm{~s}$ (nozzle moving time, $t_{n}=1.8 \mathrm{~s}$ )

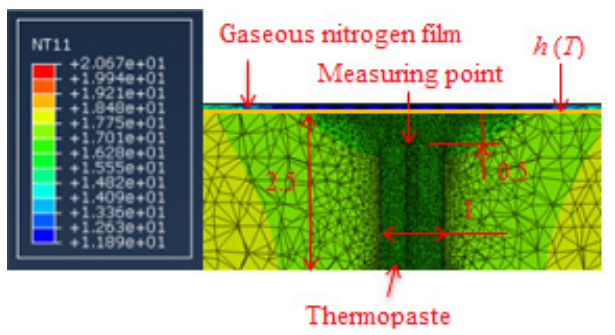

Fig. 10. Temperature distribution across the Inconel 718 plate after numerical simulation, $t_{\text {sim }}=2.4 \mathrm{~s}$

At the transition between Inconel 718 and the thermopaste, the heat conductivity was defined, as well as at the transition between the thermopaste and the thermocouple.

The comparison between the experimental and the calculated $T(t)$ curve and consequently the values for the heat transfer coefficient between the coolant and the workpiece surface will be presented in the following part of the paper.

\section{RESULTS}

Fig. 11 shows the experimental and the simulation temperature-time $T(t)$ distribution curves. In the numerical simulation, a layer $(l=0.1 \mathrm{~mm})$, which describes the gaseous phase of the nitrogen, has been designed.

A higher inconsistency between the curves occurs only in the initial part $(t=0 \mathrm{~s}$ to $0.9 \mathrm{~s})$, where the experimental curve $T_{\text {exp }}(t)$ reaches a higher temperature gradient. This error in the numerical simulation is conditioned by the design of the gaseous nitrogen film which was constantly placed on the workpiece and did not change geometrically (simplification). The fitting between $T_{\exp }(t)$ and $T_{\text {sim }}(t)$ curves is appropriate, given the simplification of the simulation conditions. At the start of the experiments, a preliminary experiment with input data: $v=1 \mathrm{~m} / \mathrm{min}$ and $d=0.5 \mathrm{~mm}$ was conducted.

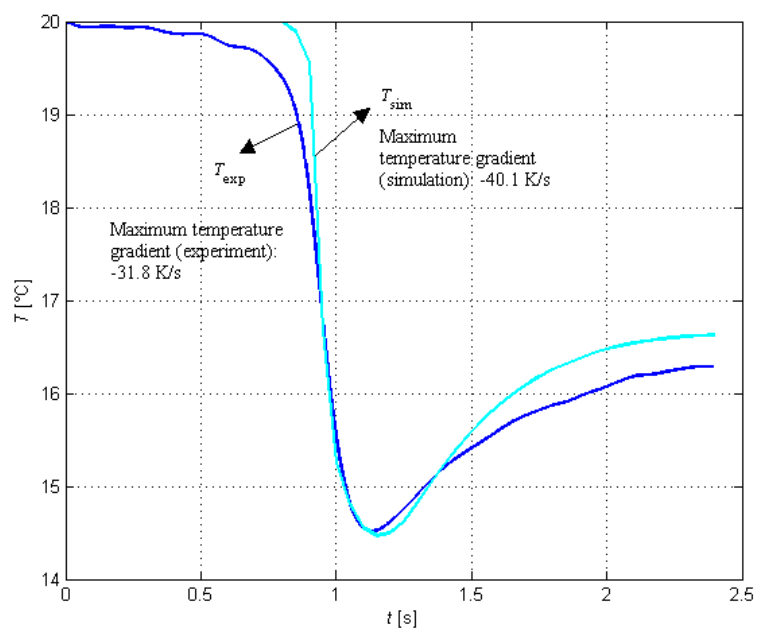

Fig. 11. The comparison between experimental curve $T_{\text {exp }}(t)$ and simulation curve $T_{\text {sim }}(t)$

Based on this experiment, a numerical simulation has been created to confirm the trend of the $T_{\text {sim }}(t)$ curve for $v=5 \mathrm{~m} / \mathrm{min}$ and $d=0.5 \mathrm{~mm}$. The trend was the same in both numerical curves and the same temperature difference as in the experiment was reached.

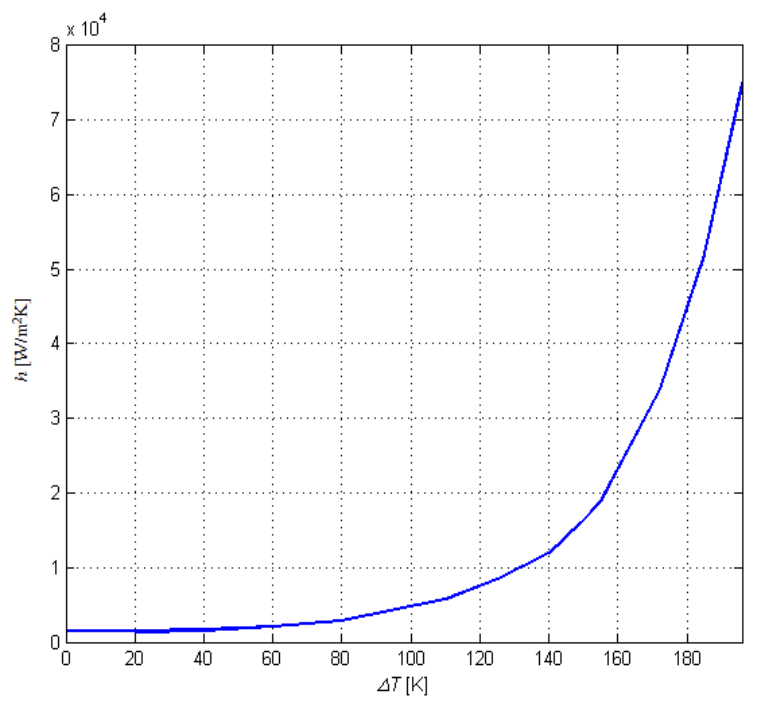

Fig. 12. Surface heat transfer coefficent in dependance of the temperature difference between liquefied nitrogen and the workpiece (Inconel 718)

According to the fitting of the two curves, the surface heat transfer coefficient between the coolant (gaseous nitrogen film) and Inconel 718 (Fig. 12) has 
been defined. The difference between the temperatures (the fluid $T_{\text {fluid }}=-196{ }^{\circ} \mathrm{C}$ and the workpiece surface $T_{\text {body }}=25{ }^{\circ} \mathrm{C}$ ) defines the surface heat transfer coefficient, calculated by the following Eq. (5) [17]:

$$
q=h\left(T_{\text {body }}-T_{\text {fluid }}\right)=h \cdot \Delta T .
$$

The comparable trend of the curve (Fig. 12) can be seen in the adapted paper [17].

\section{CONCLUSIONS}

For the past few decades, the increase of consumption of cooling lubrication fluids, which are not harmful to humans and the environment, was detected in researches. The idea has been developed in accordance to sustainable engineering. Liquefied nitrogen is one of the many media which can be used as a cooling lubrication fluid in green manufacturing. The benefits of the usage of liquefied nitrogen are: improved machinability of the material can be expected via improved (shorter) chips, reduced temperature in the cutting zone, improved surface roughness and more compressive residual stresses in the material.

The paper analyses thermal influences of liquefied nitrogen on workpiece material Inconel 718. It presents the process of solving the inverse problem for determining the surface heat transfer coefficient between liquefied nitrogen and workpiece depending on the temperature difference. The experiments where the temperature in the material was measured were performed in dependance on the different speeds of the moving nozzle across the plate.

Then the numerical simulation was designed to validate the experiment. The surface heat transfer coefficient between liquefied nitrogen and the workpiece surface was defined (based on the fitting of the experimental and simulation curves).

According to the results, the paper can give the following conclusions:

- The surface heat transfer coefficient is not a constant value but it decreases with increasing temperature of liquefied nitrogen (liquid to gas).

- The heat transfer coefficient between liquefied nitrogen and the Inconel 718 workpiece surface is the highest when nitrogen is in the liquid phase (around temperature difference $\Delta T=196{ }^{\circ} \mathrm{C}$, $\left.h=75000 \mathrm{~W} /\left(\mathrm{m}^{2} \mathrm{~K}\right)\right)$.

- Under temperature difference $160 \mathrm{~K}$, a sharp fall to around $15000 \mathrm{~W} /\left(\mathrm{m}^{2} \mathrm{~K}\right)$ can be detected, because of the nitrogen transformation from liquid to gaseous phase.
- The effect of conductance is reduced due to the formation of a gaseous nitrogen film (bubble boiling) which has got very low heat conductivity, around $0.03 \mathrm{~W} /(\mathrm{mK})$.

- The deviation between the experimental and the simulation curve is higher at the beginning of the process ( $t=0 \mathrm{~s}$ to $0.8 \mathrm{~s})$. It happens because of the nitrogen gaseous film which was being removed by the fluid jet which also cooled the workpiece surface in the experiment. In the simulation, the film was predicted and its characteristic did not change (were kept constant), therefore, such drop of temperature did not occur, contrary to the experiment.

- Summarizing the results, the limit where the heat transfer coefficient between liquefied nitrogen and the workpiece surface drops to the lowest value is when the temperature difference becomes $150 \mathrm{~K}$. From there, it is possible to detect only air because whole nitrogen evaporates and there is only force air convection $\left(1500 \mathrm{~W} /\left(\mathrm{m}^{2} \mathrm{~K}\right)\right)$.

\section{REFERENCES}

[1] Maruda, R.W., Krolczyk, G.M., Feldshtein, E., Pusavec, F., Szydlowski, M., Legutko, S., Sobczak-Kupiec, A. (2016). A study on droplets sizes, their distribution and heat exchange for minimum quantity cooling lubrication (MQCL). International Journal of Machine Tools and Manufacture, vol. 100, p. 81-92, DOI:10.1016/j.jijmachtools.2015.10.008.

[2] Maruda, R.W., Legutko, S., Krolczyk, G.M., Raos, P. (2015). Influence of cooling conditions on the machining process under MQCL and MQL conditions. Tehnički vjesnik - Technical Gazette, vol. 22, no. 4, p. 965- 970, D0l:10.17559/TV20140919143415.

[3] Pusavec, F., Deshpande, A., Yang, S., M'Saoubi, R., Kopac, J., Dillon, O.W. Jr., Jawahir, I.S. (2015). Sustainable machining of high nickel alloy - Inconel 718: Part 2 - Chip breakability and optimization. Journal of Cleaner Production, vol. 87, p. 941952, D0I:10.1016/j.jclepro.2014.10.085.

[4] Pusavec, F., Courbon, C., Rech, J., Kopac, J., Jawahir, I.S. (2014). Importance of the nitrogen phase on the cryogenic machining performance. ASME International Manufacturing Science and Engineering Conference, D0l:10.1115/ MSEC2014-3992.

[5] Pusavec, F., Hamdi, H., Kopac, J., Jawahir, I.S. (2011). Surface integrity in cryogenic machining of nickel- based alloy - Inconel 718. Journal of Material Processing Technology, vol. 211, no. 4, p. 773-783, D0I:10.1016/J.jmatprotec.2010.12.013.

[6] Thakur, A., Gangopadhyay, S. (2015). State-of-the-art in surface integrity in machining of nickel-based super alloys. International Journal of Machine Tools and Manufacture, vol. 100, p. 25-54, D0l:10.1016/j.jimachtools.2015.10.001.

[7] Barron, R.F. (1999). Cryogenic Heat Transfer Coefficient. Taylor and Francis, Philadelphia. 
[8] Yildiz, Y., Nalbant, M. (2008). A review of cryogenic cooling in machining processes. International Journal of Machine Tools and Manafacture, vol. 48, no. 9, p. 947-964, D0l:10.1016/j. ijmachtools.2008.01.008.

[9] Ding, Y., Hong, S.Y. (1995). A Study of the Cutting Temperatures in Machining Processes Cooled by Liquid Nitrogen. Socety of Mechanical Engineering, p. 95-113.

[10] Dhokia, V., Shokrani, C.A., Correa Paulino, D., Newman, S. (2012). Effects of Cryogenic Cooling on the Surface Quality and Tool Wear in End-Milling 6061-T6 Aluminium. 22nd International Conference on Flexible Automation and Intelligent Manufacturing, p. 103-108.

[11] Pu, Z., Outeiro, J.C., Batista, A.C., Dillon, O.W. Jr., Puleo, D.A., Jawahir, I.S. (2011). Surface integrity in dry and cryogenic machining of AZ31B Mg alloy with varying cutting edge radius tools. Procedia Engineering, vol. 19, p. 282-287, DOI:10.1016/j.proeng.2011.11.113.

[12] Kida, M., Kikuchi, Y., Takahashi, O., Michiyoshi, I. (1981). Poolboiling heat transfer in liquid nitrogen. Journal of Nuclear Science and Technology, vol. 18, no. 7, p. 501-513, D0l:10.10 80/18811248.1981.9733284.

[13] Tsukamoto, O., Uyemura, T. (1980). Observation of bubble formation mechanism of liquid nitrogen subjected to transient heating. Advances of Cryogenic Engineering, Springer New York, p. 476-482, D0I:10.1007/978-1-4613-9856-1_57.

[14] Hong, S.Y., Ding, Y. (2001). Cooling approaches and cutting temperatures in cryogenic machining of Ti-6Al-4V. International Journal of Machine Tools and Manufacture, vol. 41, no. 10, p. 1417-1437, D0l:10.1016/S0890-6955(01)00026-8.

[15] Hong, S.Y., Ding, Y. (2001). Micro-temperature manipulation in cryogenic machining of low steel. Journal of Material Processing Technology, vol. 116, no. 1, p. 22-30, Dol:10.1016/ S0924-0136(01)00836-6.

[16] Ambrosy, F., Zanger, F., Schulze, V., Jawahir, I.S. (2014). An experimental study of cryogenic machining on nanocrystalline surface layer generation. Procedia CIRP, vol. 13, p. 169-174, D0I:10.1016/j.procir.2014.04.029.

[17] Pusavec, F., Lu, T., Courbon, C., Rech, J., Aljancic, U., Kopac, J., Jawahir, I.S. (2016): Analysis of the influence of nitrogen phase and surface heat transfer coefficient on cryogenic machining performance. Journal of Material Processing Technology, vol. 233, p. 19-28, D0I:10.1016/J.jmatprotec.2016.02.003.

[18] Leinhard, J.H. IV, Lienhard, J.H. V (2008). A Heat Transfer Textbook, $3^{\text {rd }} \mathrm{ed}$. Phlogiston Press Camridge, Massachusetts.

[19] Qpedia Thermal eMagazine (2015). Thermal-FluidsPedia Mass transfer, from http://www.qats.com/Qpedia/Qpedia_Issue96. ashx accesed on 2015-19-11.

[20] Chiavazzo, E., Ventola, L., Calignano, F. Manfredi, D., Asinari, P. (2014). A sensor for direct measurement of small convective heat fluxes: Validation and application to micro-structured surfaces. Experimental Thermal and Fluid Science, vol. 55, p. 42-53, D0I:10.1016/J.expthermflusci.2014.02.010.

[21] Maddox, D.E., Mudawar, I. (1989). Single- and two-phase convective heat transfer from smooth and enhanced microelectronic heat sources in a rectangular channel. Journal of Heat Transfer, vol. 111, no. 4, p. 1045-1052, DOI:10.1115/1.3250766.

[22] Azar, K, Tavassoli, B. (eds.) (2008) Understanding heat transfer coefficient. Qpedia Thermal eMagazine, vol. 1, no. 1-12, p. 32-35

[23] Arrazola, P.J., Özel, T., Umbrello, D., Davies, M., Jawahir, I.S. (2013). Recent advances in modeling of metal machining processes. CIRP Annals - Manufacturing Technology, vol. 62, no. 2, p. 698-715, D0l:10.1016/j.cirp.2013.05.006.

[24] Colaco, M.J., Orlande, H.R.B., Dulikravich, G.S. (2006). Inverse and optimization problems in heat transfer. Journal of Brazilian Society of Mechanical Science and Engineering, vol. 28, no. 1, p. 1-24, D0I:10.1590/S1678-58782006000100001.

[25] Arrazola, P.J., Özel, T. (2010). Investigations on the effects of friction modeling in finite element simulation of machining. International Journal of Mechanical Sciences, vol. 52, no. 1, p. 31-42, D0l:10.1016/j.ijmecsci.2009.10.001.

[26] Courbon, C., Sajn, V., Kramar, D., Rech J., Kosel, F., Kopac, J. (2011). Investigation of machining performance in high pressure jet assisted turning of Inconel 718: A numerical model. Journal of Materials Processing Technology, vol. 211, no. 11, p. 1834-1851, D0l:10.1016/j.jmatprotec.2011.06.006.

[27] Nickel Institute (2015). from http://www.nickelinstitute.org/ NickelUselnSociety, accesed on 09-02-2015.

[28] ELPRO (2015). from http://www.elpro.si/, accesed on 201510-9. 